\title{
Gene expression profiling in prognosis of distant recurrence in HR-positive and HER2-negative breast cancer patients
}

\author{
Tzu-Ting Huang ${ }^{1}$, Nicolas Pennarun ${ }^{1}$, Yu-Hao Cheng ${ }^{2}$, Cheng-Fang Horng ${ }^{1}$, Jason \\ Lei $^{3}$ and Skye Hung-Chun Cheng ${ }^{1,4}$ \\ ${ }^{1}$ Department of Medical Research, Koo Foundation Sun Yat-Sen Cancer Center, Taipei, Taiwan \\ ${ }^{2}$ Department of Medicine, Cathy General Hospital, Taipei, Taiwan \\ ${ }^{3}$ Department of Product Development, Amwise Diagnostics Pte Ltd, Taipei, Taiwan \\ ${ }^{4}$ Department of Radiation Oncology, Koo Foundation Sun Yat-Sen Cancer Center, Taipei, Taiwan \\ Correspondence to: Skye Hung-Chun Cheng, email: Skye@kfsyscc.org \\ Keywords: breast cancer; distant recurrence prediction; microarray; gene expression profiling; chemotherapy \\ Received: November 16, $2017 \quad$ Accepted: April 06, $2018 \quad$ Published: May 01, 2018 \\ Copyright: Huang et al. This is an open-access article distributed under the terms of the Creative Commons Attribution License \\ 3.0 (CC BY 3.0), which permits unrestricted use, distribution, and reproduction in any medium, provided the original author and \\ source are credited.
}

\section{ABSTRACT}

There had been several studies using gene-expression profiling in predicting distant recurrence in breast cancer. In this study, we developed an 18-gene classifier (18-GC) to predict distant recurrence of breast cancer and compared it with the 21gene panel (Oncotype $D^{\circledR}{ }^{\circledR}, O D x$ ) in performance. Included were 224 breast cancer patients with positive hormonal receptor $(\mathrm{HR}+)$ and negative human epidermal growth factor receptor 2 (HER2-). We compared the demographic, clinical, and survival information of the patients, and further compared the prediction of recurrence risk obtained by using the 18-GC with that by ODx. To have the best combined sensitivity and specificity, receiver operating characteristics (ROC) curve analysis was performed to determine the cutoff values for several breakpoint scores. For the new 18-GC, a breakpoint score of $\mathbf{2 1}$ was adopted to produce a combined highest sensitivity $(\mathbf{9 5 \%})$ and specificity (39\%) in detecting distant recurrence. At this breakpoint score, 164 of the 224 patients were classified by the 18-GC in the same risk level as by ODx, giving a concordance rate of $73 \%$. Along with patient age and tumor stage, this 18 GC was found to be an independent significant prognostic factor of distant metastasis of breast cancer. We have thus created a new gene panel assay for prediction of distant recurrence in HR+ and HER2- breast cancer patients. With a high concordance rate with ODx, this new assay may serve as a good tool for individual breast cancer patients to make an informed decision on whether adjuvant chemotherapy should be performed post-surgery.

\section{INTRODUCTION}

While breast cancer in Asia is characterized by a lower incidence rate than in the United States and Europe, $[1,2]$ it is still one of the leading causes of cancer death in Asia, particularly in Taiwan [3-5]. This disease is featured by its complexity due to the genetic heterogeneity of breast carcinomas [6]. Since a few decades ago, many geneexpression profiling studies of breast cancer have revealed the existence of four major subtypes differing markedly in prognosis: luminal-A, luminal-B, HER2-amplified, and basal-like [6], prevalence of which varies by racial/ethnic groups [7]. Among the Asian populations, prevalence of the luminal-A, luminal-B, HER2+/ER-, basal-like, and unclassified subtype has been shown to be $55-65 \%, 10$ $20 \%, 10-15 \%, 10-15 \%$, and $0-5 \%$, respectively $[8,9]$. In the current study, we focused on luminal-like breast cancer comprising the luminal-A and luminal-B subtypes, which are defined by the presence of hormonal receptor and absence of HER 2 on the plasma membrane of tumor cells 
(i.e., HR+/HER2-) by the immunohistochemistry [10]. Several studies have suggested that luminal-like cancers tend to have the most favorable prognosis and longerterm survival when compared with the other subtypes $[11,12]$. However, early-stage breast cancer patients with the luminal-like subtypes are commonly (up to 75\%) overtreated with adjuvant chemotherapy despite that recent studies have indicated that adjuvant chemotherapy may not provide significant benefit in reducing risk of recurrence $[13,14]$.

To overcome this issue, several multigene panels, such as Oncotype $\mathrm{DX}^{\circledR}(\mathrm{ODx})$, MammaPrint ${ }^{\circledR}$ and EndoPredict $^{\mathbb{B}}$ assay kits, have been developed to help clinical decision-making regarding adjuvant chemotherapy for patients with early-stage breast carcinomas. ODx (Genomic Health Inc., Redwood, CA) is a prognostic and predictive assay kit for women with HR + and HER2breast cancer. It is a 21-gene RT-PCR assay for 16 cancerrelated and five housekeeping control genes with an aim to aid physicians and patients to determine the best course of treatment by predicting the risk of distant recurrence of breast cancer. The ODx assay produces a numerical recurrence score and places patients into three categories: low-, intermediate- and high-risk [15]. Another test (MammaPrint by Agendia BV, Amsterdam, Netherlands) is a microarray-based gene-expression profiling assay that can classify the risk of distant recurrence into two categories, low and high, by analyzing 70 genes of HR+ and node-negative patients that had not received adjuvant systemic therapy [16]. The third test, EndoPredict (Myriad Genetics, Salt Lake City, UT), is a 11-gene RT-PCR test that provides prognostic information regarding the risk of distant recurrence of breast cancer to patients with HR+ and HER2- tumors [17]. The assay measures the expression of eight cancer-related and three control genes, and classifies patients under endocrine therapy into lowor high-risk of distant recurrence.

Even though all such tools can help in making treatment decision on adjuvant chemotherapy for patients with early-stage breast carcinoma, none of them was originally developed for Asian patients even though Asian people may have different mechanisms in breast cancer due to multiple factors such as ethnic, environmental, and genetic variations [18-20]. To overcome such potential limitations, we developed an 18-gene classifier (18-GC) with tumor tissues obtained from Asian breast cancer patients and compared its performance with that of ODx in predicting distant metastasis in early-stage HR+/HER2patients.

\section{RESULTS}

\section{Patient characteristics}

Two-hundred twenty-four HR+ and HER2- breast cancer patients were included in the study (Table 1) with $202(90.2 \%)$ of the patients diagnosed with no metastasis during the development of their breast cancer and $185(82.6 \%)$ treated with adjuvant chemotherapy. Among those receiving chemotherapy, 165 (89.2\%) of the patients did not develop metastasis during their follow-up.

We found that two characteristics were significantly associated with the presence of metastasis in unadjusted analysis: a) an age at 40 or younger; b) a stage of T2-T3 (Table 1). Among the patients with no metastasis, $81.2 \%$ were over 40 years old, whereas only $54.5 \%$ of the patients with metastasis were categorized in the same age group $(\mathrm{p}=0.011)$. On the other hand, probability for patients with a T2-T3 tumor stage to develop metastasis is significantly higher than that for patients with a T1 tumor stage (81.8\% with metastasis vs. $47.5 \%$ without metastasis for T2-T3 compared with $18.2 \%$ with metastasis vs. $52.5 \%$ without metastasis for $\mathrm{T} 1, \mathrm{p}=0.003$ ).

\section{Determination of the breakpoint score}

For the breakpoint determination in the original panel of the 18 genes selected previously (Table 2), we compared the ROC curves with different cutoff points that stratify patients into two groups: low- or high-risk of recurrence. We selected a breakpoint score of 21 (Figure 1) since this score minimized the distance on the ROC curve to the left top edge of the diagram and produced a combined greatest sensibility $(95.4 \%)$ and specificity $(39.1 \%)$. By using this breakpoint, 80 (35.7\%) of the 224 patients were classified as having low risk and 144 (64.3\%) high risk.

Patients classified in the intermediate-group by ODx were considered high risk when in comparison with the 18-gene panel. By using a breakpoint score of 21 in our gene panel assay, a total of 164 patients was classified in the same risk level as the ODx assay $(73.2 \%$ concordance $)$, indicating a significant agreement in the outcome predictions for individual patients (Table 3).

\section{Recurrence rate and recurrence-free survival by distant metastasis}

To evaluate the prognostic power of the 18-GC, we compared the status predicted by the 18-GC and the actual distant metastasis status (Table 4). Even though the calculated PPV at 14.6 is relatively low, the calculated NPV is relatively high at $98.8 \%$, indicating that the $18-\mathrm{GC}$ is relatively accurate in identifying patients that would not have distant metastasis in the end of clinical monitoring.

In addition, we calculated the PPV and NPV for patients who was not treated by chemotherapy $(n=39)$. Results showed that the PPV is at $10 \%$ and the NPV at $100 \%$, meaning that the $18 \mathrm{GC}$ is well precise for determining the risk if a patient will have distant 
Table 1: Characteristics of patients with and without metastasis in HR+/HER2- invasive breast carcinomas ( $\mathrm{n}=\mathbf{2 2 4}$ )

\begin{tabular}{|c|c|c|c|}
\hline \multirow{3}{*}{ Variable } & Absence of metastasis & Presence of metastasis & \multirow{3}{*}{ p-value } \\
\hline & $\mathrm{n}=\mathbf{2 0 2}$ & $\mathrm{n}=\mathbf{2 2}$ & \\
\hline & n (\%) & n (\%) & \\
\hline \multicolumn{4}{|l|}{ Age } \\
\hline$\leqq 40(n=48)$ & $38(18.8)$ & $10(45.5)$ & \multirow[t]{2}{*}{0.011} \\
\hline$>40(\mathrm{n}=176)$ & $164(81.2)$ & $12(54.5)$ & \\
\hline \multicolumn{4}{|l|}{ T stage } \\
\hline $\mathrm{T} 1(\mathrm{n}=110)$ & $106(52.5)$ & $4(18.2)$ & \multirow[t]{2}{*}{0.003} \\
\hline $\mathrm{T} 2-\mathrm{T} 3(\mathrm{n}=114)$ & $96(47.5)$ & $18(81.8)$ & \\
\hline \multicolumn{4}{|l|}{ N stage } \\
\hline N0 $(n=130)$ & $119(58.9)$ & $11(50.0)$ & \multirow[t]{2}{*}{0.421} \\
\hline $\mathrm{N} 1(\mathrm{n}=94)$ & $83(41.1)$ & $11(50.0)$ & \\
\hline \multicolumn{4}{|l|}{ Chemotherapy } \\
\hline No $(n=39)$ & $37(18.3)$ & $2(9.1)$ & \multirow[t]{2}{*}{0.382} \\
\hline Yes $(\mathrm{n}=185)$ & $165(81.7)$ & $20(90.9)$ & \\
\hline \multicolumn{4}{|l|}{ Radiotherapy } \\
\hline No $(n=93)$ & $83(41.1)$ & $10(45.5)$ & \multirow[t]{2}{*}{0.693} \\
\hline Yes $(n=131)$ & $119(58.9)$ & $12(54.5)$ & \\
\hline \multicolumn{4}{|l|}{ Hormone therapy } \\
\hline No $(n=9)$ & $8(4.0)$ & $1(4.5)$ & \multirow[t]{2}{*}{1.000} \\
\hline Yes $(n=215)$ & $194(96.0)$ & $21(94.5)$ & \\
\hline \multicolumn{4}{|l|}{ Lymph vessel invasion } \\
\hline Nil/ Minimal (n=182) & $166(82.2)$ & $16(72.7)$ & \multirow[t]{2}{*}{0.263} \\
\hline Prominent $(n=42)$ & $36(17.8)$ & $6(27.3)$ & \\
\hline \multicolumn{4}{|l|}{ ER status } \\
\hline Negative $(n=5)$ & $5(2.5)$ & $0(0.0)$ & \multirow[t]{2}{*}{1.000} \\
\hline Positive $(\mathrm{n}=219)$ & $197(97.5)$ & $22(100.0)$ & \\
\hline \multicolumn{4}{|l|}{ PR status } \\
\hline Negative $(n=40)$ & $35(17.3)$ & $5(22.7)$ & \multirow[t]{2}{*}{0.558} \\
\hline Positive $(n=184)$ & $167(82.7)$ & $17(77.3)$ & \\
\hline
\end{tabular}

metastasis, especially for patients classified as low-risk (Table 5).

We then performed a univariate and multivariate Cox proportional-hazards analysis for the factors of age, tumor stage, lymph node status, tumor grade, lymph vessel invasion, and risk classification by the 18 -GC
(Table 6). In the unadjusted model, we found that age at diagnosis, tumor stage, and classification by the 18$\mathrm{GC}$ are significant prognostic factors of recurrence-free survival by distant metastasis. In the adjusted model, age at diagnosis, tumor stage and the $18-\mathrm{GC}$ remain significantly associated with recurrence. Patients at age 
Table 2: Genes selected for gene-expression profiling analysis

\begin{tabular}{|c|c|c|}
\hline Gene symbol & Gene title & GenBank accession number \\
\hline TRPV6 & $\begin{array}{l}\text { Transient receptor potential cation } \\
\text { channel, subfamily } \mathrm{V} \text {, member } 6\end{array}$ & NM_018646 \\
\hline DDX39 & $\begin{array}{c}\text { DEAD (Asp-Glu-Ala-Asp) box } \\
\text { polypeptide } 39\end{array}$ & NM_005804 \\
\hline BUB1B & $\begin{array}{c}\text { Budding uninhibited by benzimidazoles1 } \\
\text { homolog beta (yeast) }\end{array}$ & NM_001211 \\
\hline CCR1 & Chemokine (C-C motif) receptor 1 & NM_001295 \\
\hline STIL & SCL/TAL1 interrupting locus & NM_003035 \\
\hline BLM & Bloom syndrome & NM_000057 \\
\hline C16ORF7 & Chromosome 16 open reading frame 7 & NM_004913 \\
\hline PIM1 & Pim-1 oncogene & NM_002648 \\
\hline TPX2 & TPX2, microtubule associated & NM_012112 \\
\hline PTI1 & Homo sapiens elongation factor 1 -alpha 1 & NM_001402 \\
\hline TCF3 & $\begin{array}{c}\text { Transcription factor } 3(\mathrm{E} 2 \mathrm{~A} \\
\text { immunoglobulinenhancer binding factors } \\
\mathrm{E} 12 / \mathrm{E} 47)\end{array}$ & NM_003200 \\
\hline CCNB1 & Cyclin B1 & NM_031966 \\
\hline DTX2 & Deltex 2, E3 Ubiquitin Ligase & NM_020892 \\
\hline ENSA & Endosulfine alpha & NM_004436 \\
\hline RCHY1 & $\begin{array}{c}\text { Ring Finger And CHY Zinc Finger } \\
\text { Domain Containing 1, E3 Ubiquitin } \\
\text { Protein Ligase }\end{array}$ & NM_015436 \\
\hline NFATC2IP & $\begin{array}{c}\text { Nuclear Factor Of Activated T-Cells, } \\
\text { Cytoplasmic, Calcineurin-Dependent } 2 \\
\text { Interacting Protein }\end{array}$ & NM_032815 \\
\hline OBSL1 & Obscurin-like 1 & NM_015311 \\
\hline MMP15 & $\begin{array}{c}\text { Matrix Metallopeptidase } 15 \text { (Membrane- } \\
\text { Inserted) }\end{array}$ & NM_002428 \\
\hline
\end{tabular}

40 or younger upon diagnosis had worse breast cancerrecurrence survival $(\mathrm{HR}=3.2 ; 95 \% \mathrm{CI}=1.4-7.4)$ than those older than 40. Similarly, patients with T2-T3 breast cancer $(\mathrm{HR}=3.3 ; 95 \% \mathrm{CI}=1.1-10.2)$ had worse prognosis than those with $\mathrm{T} 1$ breast cancer. A score equal to or higher than 21 by the $18-\mathrm{GC}$ is a significant factor of shorter recurrence-free survival $(\mathrm{HR}=11.7$; $95 \% \mathrm{CI}=1.5-89.9)$ after adjustment for other clinical and pathological variables.

A forest plot of the HRs obtained from exploratory subgroup analyses for recurrence-free survival is shown in Figure 2. The results indicate that prominent lymph vessel invasions, tumor grade, and lymph node stage were no longer significant prognostic factors in some subgroups. A possible reason for this observation is that N1 patient usually would receive more adjuvant chemotherapy and radiotherapy than N0 patients. In contrast, the 18-gene panel classification, T2-T3 stage, and age at 40 or younger remain significant factors and might be important confounders for recurrence prognosis in breast cancer.

Recurrence-free survival rates were recorded at the 3-, 6-, and 9-year time points (Figure 3). It was found that patients classified as having low risk of recurrence by the 18-GC had high survival rates (0.960) even after nine years (Figure 3 ). In contrast, those classified as having 
high risk, the survival rates declined constantly over time and reached 0.772 at year nine (Figure 3 ). The survival probability of the low- and high-risk patients is plotted against the disease-free survival time.

\section{DISCUSSION}

Early-stage patients with the luminal-like subtypes of breast cancer are commonly overtreated with adjuvant chemotherapy [14]. To overcome this issue, genomic assays, including ODx, have been utilized to predict the recurrence risk of early-stage breast cancer. They can help patients to avoid the potential adverse toxicity from chemotherapy when the recurrence risk and treatment benefit is low [24]. On the other hand, such prognostic genomic assays should not miss to identify patients that are at high risk of recurrence and could benefit from chemotherapy [25].

Nevertheless, there may be differences in gene expression profiles among different ethnic groups. For example, ODx has been shown to overestimate the risk of recurrence in Asian patients [26]. Even in the intermediaterisk patients, the 10 -year distant metastatic rate is $0 \%$. Furthermore, Japanese women have been reported to have better survival according to the SEER data between 19731994 [27]. A recent study has also shown that the breast cancer-specific deaths in stage-I patients at year 7 in white, black, and Asian women are significantly different (hazard ratios of $1,1.57$ and 0.60 , respectively) [18]. It may thus be important to have a prognostic kit specifically for Asian breast cancer patients.

To that end, based upon an Asian breast cancer patient cohort, we have developed a kit for expression profiling of a panel of 18 genes with an aim to predict distant recurrence risk in luminal-like breast cancer patients. To test the prognostic power of this 18-GC, we included 224 patients and analyzed the association of its prediction with the actual metastasis outcome retrospectively. It was found that this $18-\mathrm{GC}$ is a significant independent prognostic factor of distant metastasis (Table 5; Figure 2). Further, at the breakpoint score of 21, this 18-gene panel classified 164 patients into the same risk group as did the 21-gene ODx panel, giving a concordance rate of $73 \%$. Despite the relatively high concordance rate between the 18-GC and the ODx assay, it is noteworthy that 50 out 80 patients classified as having low risk by the 18-GC were classified as having high risk by ODx. These patients would be recommended to

\section{8-Gene score (recurrence cutoff score of 21) Oncotype Dx panel (recurrence cutoff score of 18)}
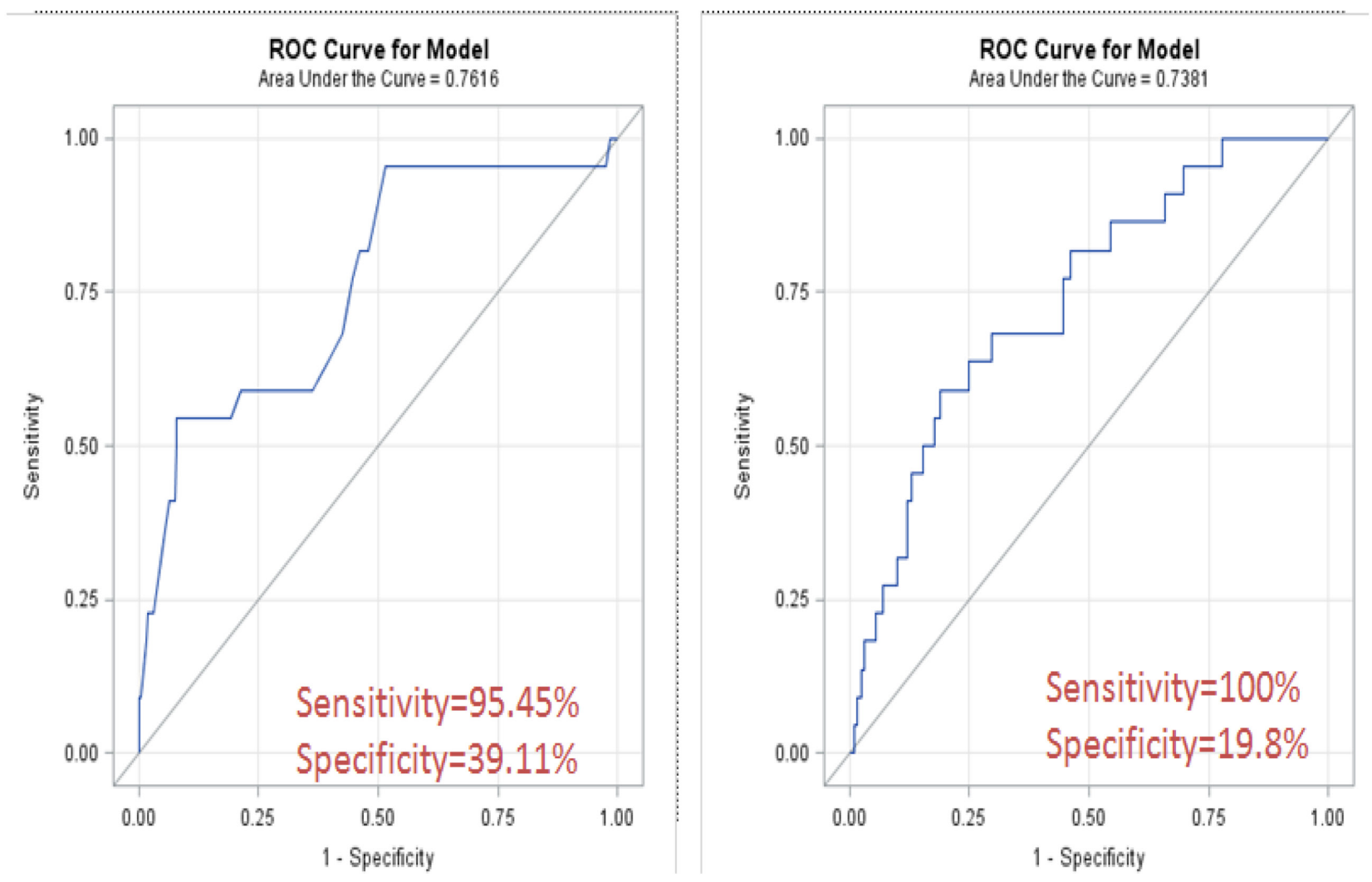

Figure 1: ROC curve analyses of the 18-GC and ODx. 
Table 3: Concordance between the 18-GC and ODx

\begin{tabular}{lcccc}
\hline & Risk group & & 18-gene classifier & \\
\cline { 3 - 5 } & & Low $(<\mathbf{2 1})$ & High $(\geqq 21)$ & $40(17.9 \%)$ \\
\hline Oncotype & Low $(<18)$ & $30(75.0 \%)$ & $10(25.0 \%)$ & $184(82.1 \%)$ \\
DX & High $(\geqq 18)$ & $50(27.2 \%)$ & $134(72.8 \%)$ & $224(100 \%)$ \\
\hline
\end{tabular}

Table 4: Concordance between predictions by the 18-GC and the actual clinical distant metastasis outcomes

\begin{tabular}{|c|c|c|c|c|}
\hline & \multicolumn{3}{|c|}{ Distant metastasis } & \multirow{2}{*}{ Total } \\
\hline & Risk group & No & Yes & \\
\hline \multirow[t]{3}{*}{ 18-gene classifier } & Low $(<21)$ & $79(98.8 \%)$ & $1(1.2 \%)$ & $80(35.7 \%)$ \\
\hline & $\operatorname{High}(>=21)$ & $123(85.4 \%)$ & $21(14.6 \%)$ & $144(64.3 \%)$ \\
\hline & Total & $202(90.2 \%)$ & $22(9.8 \%)$ & $224(100 \%)$ \\
\hline
\end{tabular}

Table 5: Concordance between predictions by the 18-GC and the actual clinical distant metastasis outcomes for patients without adjuvant chemotherapy

\begin{tabular}{|c|c|c|c|c|}
\hline & \multicolumn{3}{|c|}{ Distant metastasis } & \multirow{2}{*}{ Total } \\
\hline & Risk group & No & Yes & \\
\hline \multirow[t]{3}{*}{ 18-gene classifier } & Low $(<21)$ & $19(100 \%)$ & $0(0 \%)$ & $19(48.7 \%)$ \\
\hline & $\operatorname{High}(>=21)$ & $18(90 \%)$ & $2(10 \%)$ & $20(51.3 \%)$ \\
\hline & Total & $37(94.9 \%)$ & $2(5.1 \%)$ & $39(100 \%)$ \\
\hline
\end{tabular}

Table 6: Cox proportional hazard models for recurrence-free survival

\begin{tabular}{|c|c|c|c|c|}
\hline \multirow{2}{*}{ Variable } & \multicolumn{2}{|c|}{ Crude } & \multicolumn{2}{|c|}{ Adjusted } \\
\hline & HR $(95 \%$ CI) & P-value & HR $(95 \%$ CI $)$ & P-value \\
\hline \multicolumn{5}{|l|}{ Age } \\
\hline$\leqq 40(n=48)$ & $3.2(1.4-7.4)$ & \multirow{2}{*}{0.007} & $2.7(1.1-6.3)$ & \multirow{2}{*}{0.025} \\
\hline$>40(\mathrm{n}=176)$ & 1 (Reference) & & 1 (Reference) & \\
\hline \multicolumn{5}{|l|}{ T stage } \\
\hline $\mathrm{T} 1(\mathrm{n}=110)$ & 1 (Reference) & \multirow{2}{*}{0.009} & 1 (Reference) & \multirow{2}{*}{0.039} \\
\hline T2-T3 $(n=114)$ & $4.3(1.4-12.6)$ & & $3.3(1.1-10.2)$ & \\
\hline \multicolumn{5}{|l|}{ N stage } \\
\hline N0 $(n=130)$ & 1 (Reference) & \multirow{2}{*}{0.439} & 1 (Reference) & \multirow{2}{*}{0.294} \\
\hline N1 $(n=94)$ & $1.4(0.6-3.2)$ & & $0.6(0.2-1.5)$ & \\
\hline \multicolumn{5}{|l|}{ Tumor grade } \\
\hline $1(n=59)$ & 1 (Reference) & \multirow{3}{*}{0.396} & 1 (Reference) & \multirow{3}{*}{0.614} \\
\hline $2(\mathrm{n}=106)$ & $2.2(0.6-8.0)$ & & $1.4(0.4-5.0)$ & \\
\hline $3(n=59)$ & $2.4(0.6-9.4)$ & & $0.8(0.2-3.4)$ & \\
\hline \multicolumn{5}{|l|}{ Lymph vessel invasion } \\
\hline Nil/ Minimal (n=182) & 1 (Reference) & \multirow{2}{*}{0.232} & 1 (Reference) & \multirow{2}{*}{0.298} \\
\hline Prominent $(n=42)$ & $1.8(0.7-4.5)$ & & $1.7(0.6-4.8)$ & \\
\hline \multicolumn{5}{|l|}{ 18-gene classifier } \\
\hline$<21(\mathrm{n}=80)$ & 1 (Reference) & \multirow{2}{*}{0.015} & 1 (Reference) & \multirow{2}{*}{0.018} \\
\hline$\geqq 21(\mathrm{n}=144)$ & $12.1(1.6-89.9)$ & & $11.7(1.5-89.9)$ & \\
\hline
\end{tabular}

Abbreviations: HR, hazard ratio; CI, confidence interval. 


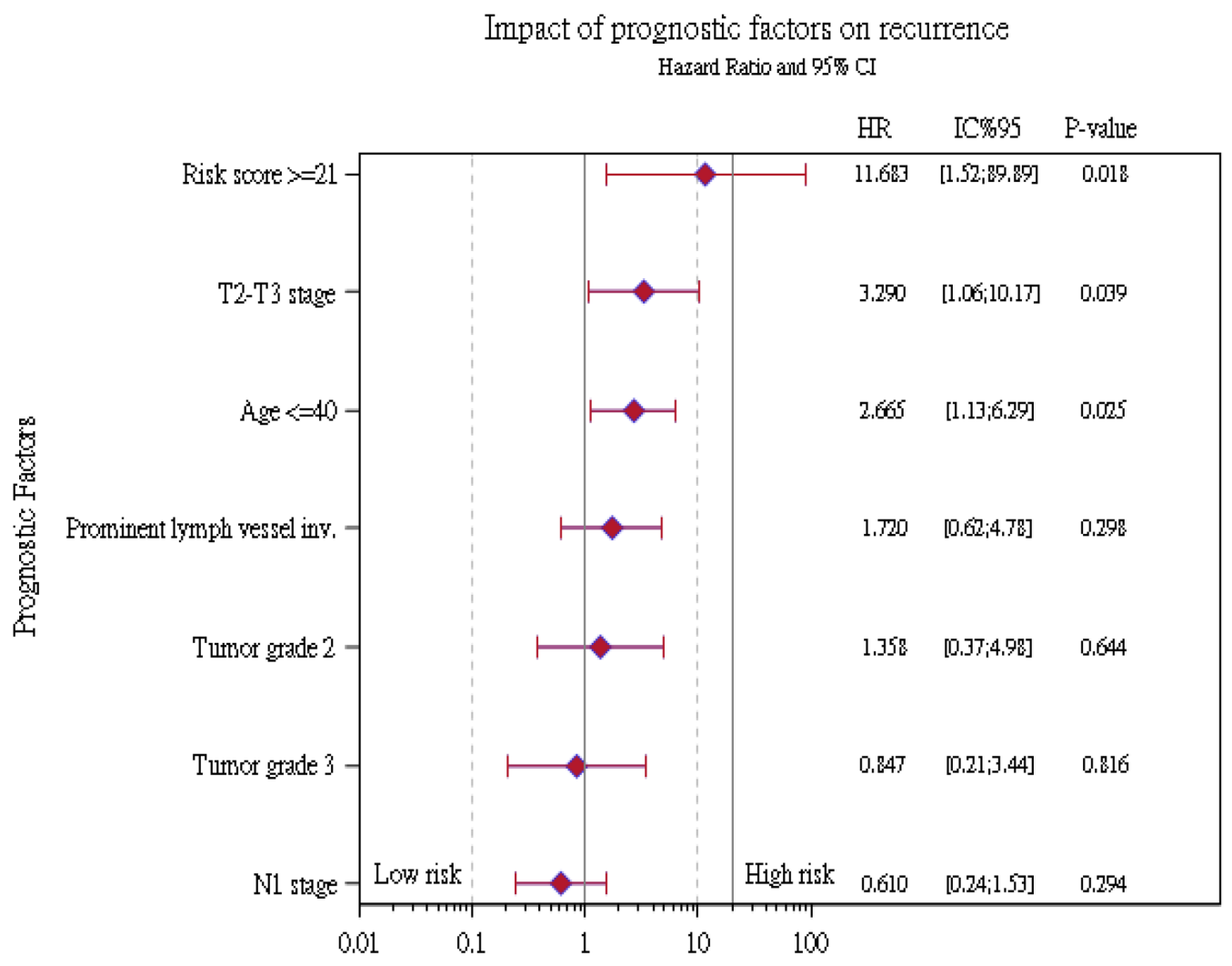

Figure 2: Summary of recurrence hazard ratios for different risk factors in subgroup analyses.

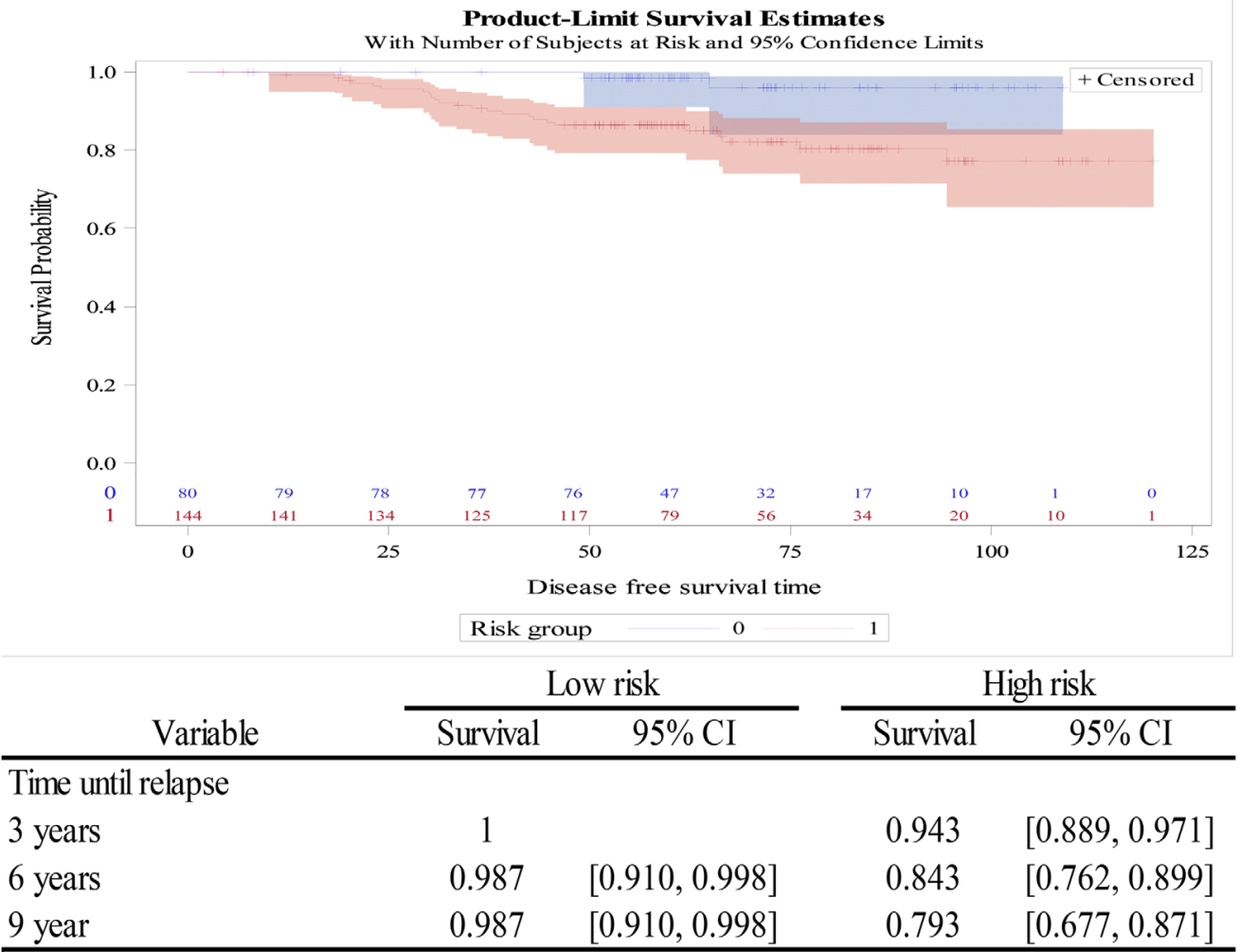

Abbreviations: HR, hazard ratio; CI, confidence interval

Figure 3: Survival plot analysis of low- and high-risk patients as determined by the 18-gene classifier. 
receive adjuvant chemotherapy if based on the risk scores assigned by ODx. However, from the retrospective clinical outcomes, it was found that patients assigned as having low risk of distance recurrence by the 18-GC had a high (98.8\%) distant metastasis-free rate (Table 4) and a high probability of a long recurrence-free survival (Table 6 and Figure 3), which contrasts with the phenomenon observed among luminal-like (both the luminal-A and -B subtypes) breast cancer patients whose survival decreases constantly over time even though they had been classified in the lowrisk group by ODx [28]. Even though a prospective study with a larger patient cohort is warranted, the new panel that we developed may serve as a good tool for breast cancer patients, especially those with an Asian ethnicity, to make a personalized and informed decision on whether chemotherapy should be performed.

\section{MATERIALS AND METHODS}

\section{Patient selection}

Retrospectively we included in this study a total of 224 luminal-like (HR+/HER2- ) and T1-3N0-1 breast cancer patients treated at Koo Foundation Sun Yat-Sen Cancer Center (KFSYSCC) in Taipei, Taiwan between 2005 and 2012, for evaluation of the 18-GC developed in our institute [21]. The institutional review board of KFSYSCC reviewed and approved the protocol and informed consent documents for the study. Eligible patients had invasive breast cancer; surgery as first treatment (mastectomy or breast-conserving surgery); a positive test result for estrogen or progesterone receptors (HR+); a negative test result for HER2 (HER2-); a few positive lymph nodes between 0 and 3. Patients with an N2, N3 or M1 stage and treated with pre-operative chemotherapy were excluded.

\section{The 18-gene classifier}

Development of the 18-GC has been reported previously [21]. Briefly, it was developed based on 135 breast cancer patients, including 112 patients treated in KFSYSCC, who developed no and 23 patients who developed LRR. Including a total of 18 recurrence-related genes, the 18-GC is a multifunctional gene panel that is associated with cell cycle and proliferation (DDX39, BUB1B, STIL, TPX2, CCNB1), oncogenic process (BLM, TCF3, PIM1, RCHY1, PTI1), inflammation and immune response (CCR1, NFATC2IP), cell-cell interaction (TRPV6, OBSL1, MMP15), apoptosis (C16ORF7, DTX2) and metabolism (ENSA) [21]. For risk classification, each gene was assigned a weight according to the Cox proportional hazards model to assemble the 18-gene scoring algorithm. With a range of risk scores between zero and 56, the breakpoint value of 21 was used to separate the low- from the high-risk category of distant recurrence. The algorithm of $18-\mathrm{GC}$ is shown as below: [21]

18-gene score $=4 \times$ TRPV6 $+3 \times$ DDX39 $+8 \times$ $\mathrm{BUB} 1 \mathrm{~B}+\mathrm{CCR} 1+\mathrm{STIL}+3 \times \mathrm{BLM}+11 \times \mathrm{C} 16 \mathrm{ORF} 7$ $+4 \times$ PIM1 1 TPX2 + $2 \times$ PTI $1+2 \times$ TCF $3+$ CCNB 1 $+\mathrm{DTX} 2+2 \times \mathrm{ENSA}+5 \times \mathrm{RCHY} 1+4 \times \mathrm{NFATC} 2 \mathrm{IP}+$ OBSL1 $+2 \times$ MMP15

Unlike ODx, we did not include an intermediate risk group because it is usually binary in clinic decisionmaking. By adopting the same statistical predictive model used by Paik et al [22], the raw recurrence score $(X i)$ is first calculated by using the following expression:

$X i=0.47 \times \mathrm{GRB} 7$ group score $-0.34 \times$ ER group score $+1.04 \times$ proliferation group score $+0.10 \times$ invasion group score $+0.05 \times$ CD68 $-0.08 \times$ GSTM 1 $-0.07 \times$ BAG.

The final recurrence score $(Y i)$ was then calculated by transforming $X i$ using the following expression:

$$
Y i=(X i-5.1031)+100 \times \frac{1}{10.7148-5.103}
$$

\section{Prognostic factors}

Along with the demographic and clinical variables previously identified with a prognostic value for distant recurrence (such as age at the diagnosis: $\leqq 40$ vs. $>40$ years old; tumor stage: T1 vs. T2-T3; lymph nodes: N0 vs. N1; tumor grade: grade 1 vs. grade 2 vs. grade 3 ; prominent vs. nil/focal lymph vessel invasion), the classification by our 18-GC (low vs. high risk) was included for analysis.

\section{Statistical analysis}

The demographic, clinical, and survival information were collected and analyzed among patients with and without metastasis. Crude and adjusted Cox analyses were used to compare patients in the low- and high-risk groups assigned by the 18-GC. ROC curve analyses were then performed to identify the optimal breakpoint [23]. We then evaluated sensitivity, specificity, accuracy, negative predictive value (NPV), positive predictive value (PPV), and the area under the curve (AUC) to determine how well the new 18-GC prediction model performs as compared with the ODx assay. All the statistical analyses $(\mathrm{p}<0.05)$ were performed using SAS Software, version 9.4.

\section{CONCLUSION}

We have created an 18-GC for predicting the risk of distant recurrence in luminal-like breast cancer patients. Even though a study with a larger patient cohort conducted in a prospective way is warranted, the new 18-GC panel assay has the potential to become a good prognosis predictor for breast cancer patients, especially those of an Asian descent, to determine whether a given patient needs adjuvant chemotherapy. 


\section{Author contributions}

Conceptualization: Skye Hung-Chun Cheng.

Data curation: Skye Hung-Chun Cheng, TzuTing Huang, Yu-Hao Cheng, Chen-Fang Horng, Nicolas Pennarun.

Formal analysis: Skye Hung-Chun Cheng, Tzu-Ting

Huang, Chen-Fang Horng, Nicolas Pennarun.

Funding acquisition: Skye Hung-Chun Cheng.

Investigation: Skye Hung-Chun Cheng, Tzu-Ting

Huang, Yu-Hao Cheng, Nicolas Pennarun.

Methodology: Skye Hung-Chun Cheng, Tzu-Ting

Huang, Chen-Fang Horng.

Project administration: Skye Hung-Chun Cheng,

Chen-Fang Horng.

Resources: Skye Hung-Chun Cheng.

Software: Tzu-Ting Huang, Chen-Fang Horng.

Supervision: Skye Hung-Chun Cheng.

Validation: Tzu-Ting Huang.

Visualization: Yu-Hao Cheng.

Writing - original draft: Yu-Hao Cheng.

Writing - review \& editing: Skye Hung-Chun Cheng, Jason Lei.

\section{ACKNOWLEDGMENTS}

The authors thank the multidisciplinary breast cancer team at the Koo Foundation Sun Yat-Sen Cancer Center (KF-SYSCC): (1) Patient care and sample collections: Drs. Chi-Min Chen, Ben-Long Yu, Tsung-Yen Cheng, and Tzu-Jung Tsai (Department of Surgery); Drs. Wan-Chen Tsai and Christopher KJ Lin (Department of Radiology); Drs. James J. Jian and Yu-Chen Tsai (Department of Radiation Oncology); (2) Data management and quality control: Yen-Chun Lin; (3) Tumor Bank: Theresa M. Tsai; and (4) Microarray Laboratory: Lih-Chian Wu and Dr. Kuo Jan Kao.

\section{CONFLICTS OF INTEREST}

The author (SHC) owns a patent relating to the content of this manuscript (Taiwan patent number: 104115832). None of the authors has any conflicts of interests in this research, either financial or non-financial.

\section{FUNDING}

This research was supported by the research fund of the Ministry of Science and Technology (NSC 102-3114Y-368-001) of the Republic of China (Taiwan).

\section{REFERENCES}

1. Leong SP, Shen ZZ, Liu TJ, Agarwal G, Tajima T, Paik NS, Sandelin K, Derossis A, Cody H, Foulkes WD. Is breast cancer the same disease in Asian and Western countries? World J Surg. 2010; 34:2308-24.

2. Kim Y, Yoo KY, Goodman MT. Differences in incidence, mortality and survival of breast cancer by regions and countries in Asia and contributing factors. Asian Pac J Cancer Prev. 2015; 16:2857-70.

3. Binns C, Low WY, Lee MK. Breast cancer: an increasing public health problem in the Asia Pacific region. Asia Pac J Public Health. 2013; 25:364-7.

4. Chiang CJ, Lo WC, Yang YW, You SL, Chen CJ, Lai MS. Incidence and survival of adult cancer patients in Taiwan, 2002-2012. J Formos Med Assoc. 2016; 115:1076-88.

5. Shen YC, Chang CJ, Hsu C, Cheng CC, Chiu CF, Cheng AL. Significant difference in the trends of female breast cancer incidence between Taiwanese and Caucasian Americans: implications from age-period-cohort analysis. Cancer Epidemiol Biomarkers Prev. 2005; 14:1986-90.

6. Cancer Genome Atlas Network. Comprehensive molecular portraits of human breast tumours. Nature. 2012; 490:61-70.

7. Parise CA, Bauer KR, Brown MM, Caggiano V. Breast cancer subtypes as defined by the estrogen receptor (ER), progesterone receptor (PR), and the human epidermal growth factor receptor 2 (HER2) among women with invasive breast cancer in California, 1999-2004. Breast J. 2009; 15:593-602.

8. Telli ML, Chang ET, Kurian AW, Keegan TH, McClure LA, Lichtensztajn D, Ford JM, Gomez SL. Asian ethnicity and breast cancer subtypes: a study from the California Cancer Registry. Breast Cancer Res Treat. 2011; 127:471-8.

9. Lin CH, Liau JY, Lu YS, Huang CS, Lee WC, Kuo KT, Shen YC, Kuo SH, Lan C, Liu JM, Kuo WH, Chang KJ, Cheng AL. Molecular subtypes of breast cancer emerging in young women in Taiwan: evidence for more than just westernization as a reason for the disease in Asia. Cancer Epidemiol Biomarkers Prev. 2009; 18:1807-14.

10. Arvold ND, Taghian AG, Niemierko A, Abi Raad RF, Sreedhara M, Nguyen PL, Bellon JR, Wong JS, Smith BL, Harris JR. Age, breast cancer subtype approximation, and local recurrence after breast-conserving therapy. J Clin Oncol. 2011; 29:3885-91.

11. Sorlie T, Perou CM, Tibshirani R, Aas T, Geisler S, Johnsen $\mathrm{H}$, Hastie T, Eisen MB, van de Rijn M, Jeffrey SS, Thorsen $\mathrm{T}$, Quist H, Matese JC, et al. Gene expression patterns of breast carcinomas distinguish tumor subclasses with clinical implications. Proc Natl Acad Sci U S A. 2001; 98:10869-74.

12. Weigelt B, Baehner FL, Reis-Filho JS. The contribution of gene expression profiling to breast cancer classification, prognostication and prediction: a retrospective of the last decade. J Pathol. 2010; 220:263-80.

13. Cheng SH, Yu BL, Horng CF, Tsai SY, Chen CM, Chu NM, Liu MC, Huang AT. In-Depth Evaluation of the AJCC 2010 Staging System for Luminal-like Breast Cancer --- An Analysis from a Free-Standing Cancer Hospital. Journal Cancer Research and Practice. 2013; 30:21-34. 
14. Cheng SH, Yu BL, Horng CF, Tsai SY, Chen CM, Chu NM, Tsou MH, Lin CK, Shih LS, Liu MC. Long-term survival and stage I breast cancer subtypes. Journal of Cancer Research and Practice. 2016; 3:1-8.

15. Paik S, Tang G, Shak S, Kim C, Baker J, Kim W, Cronin M, Baehner FL, Watson D, Bryant J, Costantino JP, Geyer CE Jr, Wickerham DL, et al. Gene expression and benefit of chemotherapy in women with node-negative, estrogen receptor-positive breast cancer. J Clin Oncol. 2006; 24:3726-34.

16. Cardoso F, van't Veer LJ, Bogaerts J, Slaets L, Viale G, Delaloge S, Pierga JY, Brain E, Causeret S, DeLorenzi M, Glas AM, Golfinopoulos V, Goulioti T, et al. 70-Gene Signature as an Aid to Treatment Decisions in Early-Stage Breast Cancer. N Engl J Med. 2016; 375:717-29.

17. Varga Z, Sinn P, Fritzsche F, von Hochstetter A, Noske A, Schraml P, Tausch C, Trojan A, Moch H. Comparison of EndoPredict and Oncotype DX test results in hormone receptor positive invasive breast cancer. PLoS One. 2013; 8:e58483.

18. Iqbal J, Ginsburg O, Rochon PA, Sun P, Narod SA. Differences in breast cancer stage at diagnosis and cancerspecific survival by race and ethnicity in the United States. JAMA. 2015; 313:165-73.

19. Chlebowski RT, Chen Z, Anderson GL, Rohan T, Aragaki A, Lane D, Dolan NC, Paskett ED, McTiernan A, Hubbell FA, Adams-Campbell LL, Prentice R. Ethnicity and breast cancer: factors influencing differences in incidence and outcome. J Natl Cancer Inst. 2005; 97:439-48.

20. Hausauer AK, Keegan TH, Chang ET, Clarke CA. Recent breast cancer trends among Asian/Pacific Islander, Hispanic, and African-American women in the US: changes by tumor subtype. Breast Cancer Res. 2007; 9:R90.

21. Cheng SH, Horng CF, Huang TT, Huang ES, Tsou MH, Shi LS, Yu BL, Chen CM, Huang AT. An Eighteen-Gene Classifier Predicts Locoregional Recurrence in PostMastectomy Breast Cancer Patients. EBioMedicine. 2016; 5:74-81.
22. Paik S, Shak S, Tang G, Kim C, Baker J, Cronin M, Baehner FL, Walker MG, Watson D, Park T, Hiller W, Fisher ER, Wickerham DL, et al. A multigene assay to predict recurrence of tamoxifen-treated, node-negative breast cancer. N Engl J Med. 2004; 351:2817-26.

23. Perkins NJ, Schisterman EF. The inconsistency of "optimal" cutpoints obtained using two criteria based on the receiver operating characteristic curve. Am J Epidemiol. 2006; 163:670-5.

24. Pittman J, Huang E, Dressman H, Horng CF, Cheng SH, Tsou MH, Chen CM, Bild A, Iversen ES, Huang AT, Nevins JR, West M. Integrated modeling of clinical and gene expression information for personalized prediction of disease outcomes. Proc Natl Acad Sci U S A. 2004; 101:8431-6.

25. Chen C, Dhanda R, Tseng WY, Forsyth M, Patt DA. Evaluating use characteristics for the oncotype $\mathrm{dx} 21$-gene recurrence score and concordance with chemotherapy use in early-stage breast cancer. J Oncol Pract. 2013; 9:182-7.

26. Toi M, Iwata H, Yamanaka T, Masuda N, Ohno S, Nakamura S, Nakayama T, Kashiwaba M, Kamigaki S, Kuroi K; Japan Breast Cancer Research Group-Translational Research Group. Clinical significance of the 21-gene signature (Oncotype DX) in hormone receptor-positive early stage primary breast cancer in the Japanese population. Cancer. 2010; 116:3112-8.

27. Pineda MD, White E, Kristal AR, Taylor V. Asian breast cancer survival in the US: a comparison between Asian immigrants, US-born Asian Americans and Caucasians. Int J Epidemiol. 2001; 30:976-82.

28. Blows FM, Driver KE, Schmidt MK, Broeks A, van Leeuwen FE, Wesseling J, Cheang MC, Gelmon K, Nielsen TO, Blomqvist C, Heikkilä P, Heikkinen T, Nevanlinna H, et al. Subtyping of breast cancer by immunohistochemistry to investigate a relationship between subtype and short and long term survival: a collaborative analysis of data for 10,159 cases from 12 studies. PLoS Med. 2010; 7:e1000279. 